\title{
BMJ Open Awareness of diabetic retinopathy and its association with attendance for systematic screening at the public primary care setting: a cross-sectional study in Hong Kong
}

\author{
JinXiao Lian, ${ }^{1,2}$ Sarah M McGhee, ${ }^{3}$ Rita A Gangwani, ${ }^{2}$ Cindy L K Lam, ${ }^{4}$ \\ Maurice K H Yap, ${ }^{1}$ David S H Wong ${ }^{5}$
}

To cite: Lian JX, McGhee SM, Gangwani RA, et al. Awareness of diabetic retinopathy and its association with attendance for systematic screening at the public primary care setting: a cross-sectional study in Hong Kong. BMJ Open 2018;8:e019989. doi:10.1136/ bmjopen-2017-019989

\section{- Prepublication history for} this paper is available online. To view these files, please visit the journal online (http://dx.doi. org/10.1136/bmjopen-2017019989).

Received 9 0ctober 2017 Revised 27 December 2017 Accepted 2 February 2018

\section{Check for updates}

${ }^{1}$ School of Optometry, The Hong Kong Polytechnic University, Hong Kong

${ }^{2}$ Department of Ophthalmology, The University of Hong Kong, Hong Kong

${ }^{3}$ School of Public Health, The University of Hong Kong, Hong Kong

${ }^{4}$ Department of Family Medicine and Primary Care, The University of Hong Kong, Hong Kong

${ }^{5}$ Royal Liverpool University Hospital, Liverpool, UK

Correspondence to

Dr JinXiao Lian;

jinxiao.lian@polyu.edu.hk

\section{ABSTRACT}

Objective To assess the association between awareness of diabetic retinopathy (DR) and actual attendance for DR screening.

Design Cross-sectional study.

Setting Two public general outpatient clinics.

Participants The subjects were people with diabetes mellitus (DM) who participated in a randomised controlled trial, set up in 2008, to test the impact of a copayment on attendance for DR screening.

Primary and secondary outcome measures The subjects' awareness of DR was evaluated using a structured questionnaire conducted via a telephone interview. The attendance for screening was from the actual attendance data. Association between awareness and attendance for screening was determined using multivariate logistic regression model and was reported as ORs.

Results A total of 2593 participants completed the questionnaire. A total of $42.9 \%$ (1113/2593) said they would worry if they had any vision loss and $79.6 \%$ (2063/2593) knew that DM could cause blindness. Only $17.5 \%$ (453/2593) knew that treatment was available for DR and $11.5 \%$ (297/2593) knew that early DR could be asymptomatic. The importance of having a regular eye examination was acknowledged by $75.7 \%$ (1964/2593), but 34\% (881/2593) did not know how frequently their eyes should be examined. Worry about vision loss ( $\mathrm{OR}=1.72, \mathrm{P}<0.001)$, awareness of the importance of regular eye examination $(\mathrm{OR}=1.83, \mathrm{P}=0.002)$ and awareness of the frequency of eye examinations ('every year' $(\mathrm{OR}=2.64, \mathrm{P}<0.001)$ or 'every 6 months' $(\mathrm{OR}=3.27$, $\mathrm{P}<0.001)$ ) were the most significant factors associated with attendance.

Conclusions Deficits in knowledge of DR and screening were found among subjects with DM, and three awareness factors were associated with attendance for screening. These factors could be targeted for future interventions.

\section{INTRODUCTION}

According to the WHO, screening is "the presumptive identification of unrecognized

\section{Strengths and limitations of this study}

- The actual attendance data were collected prospectively, which overcame the errors in recall and reverse causality.

- The sample size was over 2000 subjects, which gave sufficient statistical power to test a number of variables indicating awareness.

- One limitation is the generalisability of the results to subjects with diabetes who are looked after in secondary care.

disease in an apparently healthy, asymptomatic population by means of tests, examinations or other procedures which can be applied rapidly'. ${ }^{1}$ An individual's awareness is postulated as one of the predisposing factors that influence the individual's behaviour, for example, attendance for screening. ${ }^{23}$

Diabetic retinopathy (DR), a common complication of diabetes mellitus (DM), has become the leading cause of new cases of blindness among people of working age in developed countries. ${ }^{4}$ However, DR can be asymptomatic until there is significant vision loss. Therefore, early detection plays an important role in preventing blindness resulting from DR. Iceland and the UK are two countries that adopted systematic DR screening early. ${ }^{5}$ Iceland has successfully reduced the prevalence of blindness in the diabetic population from $2.4 \%$ to $0.5 \%$ between 1980 and $1994 .^{5}$ The incidence of sight impairment and severe sight impairment in the diabetic population was found to be almost halved in Wales over an 8-year period up to $2015 .^{7}$ Screening for DR has also been shown to be a cost-effective intervention to prevent vision loss. ${ }^{8-10}$ 
Regular screening for DR is recommended in many clinical guidelines, ${ }^{11-13}$ but in practice only $58 \%-81 \%$ of all patients with DM were regularly screened, as reported from studies in Ireland, USA, Turkey and the Netherlands. $^{2}{ }^{14-18}$ Even in the systematic DR screening programmes in the UK, attendance rates have varied between $55 \%$ and $95 \% .{ }^{19}$ Non-attendance for screening, apart from wasting resources, was also associated with increased risk of developing sight-threatening diabetic retinopathy (STDR). ${ }^{20-22}$ Why some people do not attend is an important issue to understand and address in order to better manage the risk of DM complications and efficient resource allocation.

Awareness of DR and its implications for vision is an important prerequisite for attendance for screening, and it has been examined in subjects with diabetes, with highly variable findings across different ethnic populations. $^{2} 17$ 23-27 However, few studies have examined the association of awareness with attendance for screening. In general, lack of awareness was found to be an obstacle to attendance for screening. The types of awareness measured were knowledge of detrimental effects of DR on visual acuity, knowledge of DM on DR, whether physicians or healthcare providers had recommended regular eye examinations, awareness of the need for regular and frequency of screening, and concern for vision loss. ${ }^{2} 172628{ }^{29}$ Among those studies that examined the association between screening and awareness, attendance for screening was usually collected retrospectively from self-reported data or review of medical chart. This cannot eliminate reverse causality (ie, those who were screened have more knowledge because they went to screening rather than the knowledge itself that made them go) and potential error in recall if it was self-reported data (eg, mistaking tests for spectacle prescription for retinal examination for DR).

To date, there are few studies on awareness of DR and its association with attendance for screening in Chinese populations. ${ }^{24}{ }^{29}$ Cultural, social and geographical factors could limit generalisation of the results found elsewhere to Chinese populations. Hong Kong (HK) offers a good venue to study the response in a majority of Chinese population, where DR screening is offered through a systematic call and recall system at the public primary care level with only a small copayment. $^{3031}$

Using data collected from a randomised controlled trial (RCT) study of DR screening carried out in HK, we aimed to assess the association between awareness of DR and actual attendance for screening from a cross-sectional study.

\section{METHODS}

In 2008, we set up an RCT to test the impact of a copayment on attendance for screening. ${ }^{30}{ }^{31}$ In that study, as well as collecting information on financial barriers to attendance for screening at a public general outpatient clinic (GOPC), we asked questions on awareness of DR and screening.

\section{Participants}

The participants were people with an existing diagnosis of DM recorded in their computerised medical records and who attended one of two neighbouring public GOPCs. The whole group of 4644 subjects were randomised into a free screening group without any copayment or a pay group with a copayment of HK\$60 (about $£ 5$ ). Of these subjects, 2593 agreed to participate in the study, with 1316 in the free group and 1277 in the pay group. All the participants completed a structured questionnaire by telephone. They were then invited for DR screening with or without a copayment according to their group allocation at the end of the telephone call. Finally, 2217 subjects attended screening, an attendance rate of $85.5 \%$ $(2217 / 2593)$. The research adhered to the tenets of the Declaration of Helsinki, and all participants gave informed consent before taking part. Full details of the study design and subject recruitment are published elsewhere. $^{3031}$

\section{Data collection}

The subjects' awareness of DR and its implications was evaluated using a structured questionnaire with previously validated questions from the literature as far as possible. ${ }^{2} 1532$ These questions were translated into Chinese, and the questionnaire was piloted in face-to-face interviews on 15 randomly selected subjects with DM in the community or in a hospital-based clinic to test understanding and acceptability. No problems were found for this part.

\section{Data analysis}

A descriptive analysis was used to summarise the characteristics of participating subjects. Variables indicating awareness of DR are listed below and include nine questions, most of which have three response categories, that is, yes, no or don't know, except for a few questions as specified.

1. AD1: 'At the present time, how would you rate your eyesight using both eyes (with glasses or contact lenses, if you wear them)?' with a six-category response scale from excellent to completely blind.

2. AD2: 'Do you worry if you have any vision loss?'

3. AD3: 'Do you know if diabetes could affect blindness (retinopathy)?'

4. AD4: 'Do you think it is important to have regular eye examinations?'

5. AD5: 'Have you ever been recommended by a doctor to have regular eye examinations?'

6. AD6: 'How often do you think your eyes should be examined if you are diabetic?' with a five-scale choice from never to every 6 months and don't know.

7. AD7: 'Do you believe early diabetic retinopathy is symptomatic?' 
8. AD8: 'Do you aware that there is treatment available for diabetic retinopathy?'

9. AD9: 'Have your eyes ever been screened by a general practitioner for diabetic retinopathy?'

Most of these variables did not need recoding, except for self-rated eyesight (question $\mathrm{AD} 1$ ) for which the original six-category scale was recoded to three categories of good (including excellent and good), fair and poor (including poor, very poor and completely blind).

These variables were compared between those who did and did not attend screening by $\mathrm{X}^{2}$ test, and those variables that differed significantly between the groups were included into a multivariate logistic regression model with attendance for screening as the dependent variable. The model was adjusted for age, sex, marital status, socioeconomic status (ie, education level, occupation, whether receiving comprehensive social security assistance, family income, housing type) and the fee group allocation. Missing age (98\% complete) was replaced by the median value of the self-reported age group and used in the logistic regression model. We report ORs and their 95\% CI with a $\mathrm{P}$ value of 0.05 being considered significant. All analyses were performed using STATA V.13.

\section{RESULTS}

The 2593 participants had a mean age of 64 years, a mean duration of diabetes of 7.6 years, mean haemoglobin A1c of $7.5 \%$ and mean blood pressure of $139 / 78 \mathrm{~mm} \mathrm{Hg}$ (table 1).

Most $(2237 / 2593,86.3 \%)$ participants rated themselves to have good eyesight, $42.9 \%(1113 / 2593)$ would worry if they had any vision loss and $79.6 \%(2063 / 2593)$ knew diabetes could affect blindness (retinopathy), but only $17.5 \%(453 / 2593)$ knew treatment was available for DR and $11.5 \%$ (297/2593) knew early DR could be asymptomatic (table 2). The importance of DR screening was acknowledged by $75.7 \%$ (1964/2593), and 58.9\% (1528/2593) thought that their eyes should be examined every 6-12 months, but 34\% (881/2593) did not know how frequently their eyes should be examined. Only $15.8 \%$ (409/2593) reported having been recommended by a doctor to have a regular eye examination and $13.0 \%$ $(337 / 2593)$ to have been screened by a general practitioner (GP) for DR.

Subjects who attended DR screening reported higher proportions of worrying about vision loss $(45.7 \%$ vs $26.3 \%$, $\mathrm{P}<0.001$ ), knowing that diabetes could lead to blindness ( $80.6 \%$ vs $73.4 \%, \mathrm{P}=0.004$ ), being aware of the importance of regular eye examination $(79.0 \%$ vs $56.4 \%, \mathrm{P}<0.001)$ and the need for yearly or more frequent screening (every year: $39.6 \%$ vs $28.7 \%$; every 6 months: $22.5 \%$ vs $11.7 \%$, $\mathrm{P}<0.001)$, being recommended by a doctor to have an eye examination ( $16.2 \%$ vs $13.3 \%, \mathrm{P}=0.019$ ), and previously screened by a GP for DR $(13.7 \%$ vs $8.8 \%, \mathrm{P}=0.011)$, than those who did not attend (table 2).

In the adjusted logistic regression model, worry about vision loss $(\mathrm{OR}=1.72, \mathrm{P}<0.001)$, awareness of
Table 1 Characteristics of participants

\begin{tabular}{|c|c|c|}
\hline Variables & $\mathrm{n}=2593(\%)$ & \\
\hline Mean age (SD) & $64(11)$ & $\mathrm{n}=2540$ \\
\hline Female & $1422(54.8)$ & \\
\hline \multicolumn{3}{|l|}{ Marital status } \\
\hline Married & 1917 (73.9) & \\
\hline Single & $676(26.1)$ & \\
\hline \multicolumn{3}{|l|}{ Educational level } \\
\hline No schooling & $773(29.8)$ & \\
\hline Primary & $970(37.4)$ & \\
\hline Secondary & $733(28.3)$ & \\
\hline Sixth form and up & $117(4.5)$ & \\
\hline \multicolumn{3}{|l|}{ Current occupation } \\
\hline Employed & $847(32.7)$ & \\
\hline Retired & $908(35.0)$ & \\
\hline Home maker & $832(32.1)$ & \\
\hline Refuse to answer & $6(0.2)$ & \\
\hline Receiving welfare payments (yes) & $220(8.5)$ & \\
\hline \multicolumn{3}{|l|}{ Family income/month (HK\$) } \\
\hline 0-9999 & $815(31.4)$ & \\
\hline $10000-19999$ & $580(22.4)$ & \\
\hline 20000 or above & $310(12.0)$ & \\
\hline Refuse to answer/don't know & $888(34.3)$ & \\
\hline Duration of diabetes in years (SD) & $7.6(7.0)$ & $\mathrm{n}=2513$ \\
\hline Mean systolic blood pressure (SD) & $138.5(12.8)$ & $\mathrm{n}=2542$ \\
\hline $\begin{array}{l}\text { Mean diastolic blood pressure } \\
\text { (SD) }\end{array}$ & $78.0(8.5)$ & $\mathrm{n}=2542$ \\
\hline Haemoglobin A1c, \% (SD) & $7.5(1.3)$ & $\mathrm{n}=1852$ \\
\hline
\end{tabular}

the importance of regular eye examination $(\mathrm{OR}=1.83$, $\mathrm{P}=0.002)$ and thinking that eye examinations should be every year $(\mathrm{OR}=2.64, \mathrm{P}<0.001)$ or every 6 months $(\mathrm{OR}=3.27, \mathrm{P}<0.001)$ compared with less often were significantly associated with attendance for screening (table 3 ).

\section{DISCUSSION}

The data for this study were collected at the time when systematic DR screening was set up as a pilot in 2008 and conducted annually. We found that our subjects had good awareness of DM as a potential cause of blindness $(79.6 \%)$ and of the importance of regular eye examination $(75.7 \%)$. However, there were specific deficits in knowledge, including the fact that early DR can be asymptomatic $(11.5 \% \mathrm{knew})$ and that treatment is available for DR ( $17.5 \%$ knew). There were $58.9 \%$ subjects who thought screening should be performed at least once a year (ie, every year or every 6 months), but there was still $34 \%$ who did not know how often they should be screened. These knowledge deficits have also been identified in other populations, for example in Ireland, Turkey and USA. ${ }^{2} 1625$ Awareness of DR in our study 
Table 2 Awareness of diabetic retinopathy by attendance and non-attendance for screening

\section{Total, $\mathrm{n}=2593(\%)$ \\ Attendance for \\ No attendance for \\ screening, $\mathrm{n}=2217(\%)$ \\ screening, $n=376(\%)$ \\ P value*}

At present time, how would you rate your eyesight using both eyes (with glasses or contact lenses, if you wear them)?

$\begin{array}{lcrr}\text { Good } & 2237(86.3) & 1903(85.8) & 334(88.8) \\ \text { Fair } & 325(12.5) & 288(13.0) & 37(9.8) \\ \text { Poor } & 31(1.2) & 26(1.2) & 5(1.3)\end{array}$

\subsection{9}

Do you worry if you have any vision loss?

\begin{tabular}{|c|c|c|c|}
\hline No & $1348(52.0)$ & $1094(49.4)$ & 254 (67.6) \\
\hline Yes & $1113(42.9)$ & $1014(45.7)$ & 99 (26.3) \\
\hline Don't know & $132(5.1)$ & 109 (4.9) & $23(6.1)$ \\
\hline
\end{tabular}

Do you know if diabetes would affect blindness (retinopathy)?

\begin{tabular}{|c|c|c|c|c|}
\hline No & $25(1.0)$ & $22(1.0)$ & $3(0.8)$ & \\
\hline Yes & 2063 (79.6) & 1787 (80.6) & $276(73.4)$ & \\
\hline Don't know & 505 (19.5) & 408 (18.4) & $97(25.8)$ & 0.004 \\
\hline
\end{tabular}

Do you believe early diabetic retinopathy is symptomatic?

\begin{tabular}{|c|c|c|c|c|}
\hline No & 297 (11.5) & 245 (11.1) & $52(13.8)$ & \\
\hline Yes & 504 (19.4) & $443(20.0)$ & $61(16.2)$ & \\
\hline Don't know & $1792(69.1)$ & $1529(69.0)$ & 263 (70.0) & 0.103 \\
\hline \multicolumn{5}{|c|}{ Do you aware that there is treatment available for diabetic retinopathy? } \\
\hline No & $2140(82.5)$ & $1824(82.3)$ & $316(84.0)$ & \\
\hline Yes & $453(17.5)$ & $393(17.7)$ & $60(16.0)$ & 0.403 \\
\hline
\end{tabular}

Do you think it is important to have regular eye examinations?

$\begin{array}{lrrrr}\text { No } & 259(10.0) & 176(7.9) & 83(22.1) & \\ \text { Yes } & 1964(75.7) & 1752(79.0) & 212(56.4) & \\ \text { Don't know } & 370(14.3) & 289(13.0) & 81(21.5) & <0.001\end{array}$

How often do you think your eyes should be examined if you are diabetic?

\begin{tabular}{lccrc} 
Never & $33(1.3)$ & $22(1.0)$ & $11(2.9)$ & \\
\hline Less often & $151(5.8)$ & $94(4.2)$ & $57(15.2)$ & \\
\hline Every year & $986(38.0)$ & $878(39.6)$ & $108(28.7)$ & \\
Every 6 months & $542(20.9)$ & $498(22.5)$ & $44(11.7)$ & $<0.001$ \\
\hline Don't know & $881(34.0)$ & $725(32.7)$ & $156(41.5)$ &
\end{tabular}

Have you ever been recommended by a doctor to have regular eye examination?

\begin{tabular}{|c|c|c|c|c|}
\hline No & 2159 (83.3) & $1841(83.0)$ & 318 (84.6) & \\
\hline Yes & 409 (15.8) & 359 (16.2) & 50 (13.3) & \\
\hline Don't know & $25(1.0)$ & $17(0.8)$ & $8(2.1)$ & 0.019 \\
\hline
\end{tabular}

Have your eyes ever been screened by a general practitioner for diabetic retinopathy?

\begin{tabular}{lcccc} 
No & $2242(86.5)$ & $1903(85.8)$ & $339(90.2)$ & \\
Yes & $337(13.0)$ & $304(13.7)$ & $33(8.8)$ & \\
\hline Don't know & $14(0.5)$ & $10(0.5)$ & $4(1.1)$ & 0.011 \\
\hline
\end{tabular}

${ }^{*} \mathrm{P}$ value by $\chi^{2}$ test for the comparison between attendance and non-attendance for screening.

population was generally higher than those found in surveys conducted in mainland China. ${ }^{24} 29$ One study by Liu and $\mathrm{Chen}^{24}$ showed that only $36.6 \%(174 / 475)$ of subjects with DM were aware of DR as a diabetic complication that could result in blindness. Another study by Wang et $a l^{29}$ showed that $76.7 \%(632 / 824)$ of subjects were aware of DM affecting the eyes, but only $49.4 \%$
(407/824) thought regular eye examinations were necessary.

We identified that worry about vision loss, awareness of the importance of regular eye examinations and awareness of the frequency of screening were the most important factors associated with attendance for screening. This is consistent with studies that found subjects' awareness 
Table 3 Adjusted associations between awareness of diabetic retinopathy and attendance for screening $(n=2593)$

\begin{tabular}{|c|c|c|c|}
\hline Variable & OR $^{*}$ & $95 \% \mathrm{Cl}$ & $P$ value \\
\hline \multicolumn{4}{|c|}{ Do you worry if you have any vision loss? } \\
\hline No & 1.00 & & \\
\hline Yes & 1.72 & 1.31 to 2.26 & $<0.001$ \\
\hline Don't know & 1.04 & 0.63 to 1.70 & 0.881 \\
\hline \multicolumn{4}{|c|}{$\begin{array}{l}\text { Do you know if diabetes would affect blindness } \\
\text { (retinopathy)? }\end{array}$} \\
\hline No & 1.00 & & \\
\hline Yes & 0.48 & 0.13 to 1.69 & 0.251 \\
\hline Don’t know & 0.49 & 0.13 to 1.75 & 0.271 \\
\hline \multicolumn{4}{|c|}{$\begin{array}{l}\text { Do you think it is important to have regular eye } \\
\text { examinations? }\end{array}$} \\
\hline No & 1.00 & & \\
\hline Yes & 1.83 & 1.24 to 2.70 & 0.002 \\
\hline Don’t know & 1.17 & 0.77 to 1.77 & 0.464 \\
\hline
\end{tabular}

How often do you think your eyes should be examined if you are diabetic?

$\begin{array}{lrrr}\text { Less often } & 1.00 & & \\ \text { Never } & 0.93 & 0.40 \text { to } 2.15 & 0.858 \\ \text { Every year } & 2.64 & 1.65 \text { to } 4.22 & <0.001 \\ \text { Every 6 months } & 3.27 & 1.92 \text { to } 5.56 & <0.001 \\ \text { Don't know } & 2.11 & 1.38 \text { to } 3.25 & 0.001\end{array}$

Have you ever been recommended by a doctor to have regular eye examination?

$\begin{array}{llll}\text { No } & 1.00 & & \\ \text { Yes } & 1.03 & 0.73 \text { to } 1.46 & 0.847 \\ \text { Don't know } & 0.39 & 0.16 \text { to } 0.98 & 0.044\end{array}$

Have your eyes ever been screened by a general practitioner for diabetic retinopathy?

\begin{tabular}{llll} 
No & 1.00 & & \\
Yes & 1.16 & 0.78 to 1.73 & 0.457 \\
Don't know & 0.80 & 0.23 to 2.74 & 0.718 \\
\hline
\end{tabular}

*The logistic regression model is adjusted for demographic variables (age, sex, marital status), socioeconomic status (education level, occupation, whether receiving comprehensive social security assistance, family income, housing type) and whether charged a copayment for screening.

of eye examinations being needed every 6 months was a significant predictor for receiving DR screening in Ireland $^{2}$ and that subjects' awareness of needing an eye examination every 12 months was significantly associated with having a dilated eye examination in the USA. ${ }^{28}$ However, we did not find an association between a doctor's recommendation to have a regular eye examination and attendance for screening as reported in other studies. ${ }^{2}{ }^{1728}$ This may be because we also examined other awareness factors together in the same model. However, the proportions who reported a previous screening by a GP or that they had been recommended to have regular eye examinations by a doctor were both less than $20 \%$ in the attenders and even lower in the non-attenders when there was no systematic DR screening. A subject's awareness of DR could be obtained from different sources, but a doctor's or healthcare provider's recommendation might be one of the most important sources and this may need to be strengthened.

The strengths of this study are that the actual attendance data were collected prospectively, which overcame the errors in recall and reverse causality inherent in some previous studies. We had over 2000 subjects, which provided sufficient statistical power to test a number of variables indicating awareness. One limitation is the generalisability of the results to subjects with DM throughout HK. Our study took place in the Hong Kong West Cluster, only one of the seven clusters of the public hospital system. However, in general, GOPC attendees across clusters have some similarities in that they are more likely to be of low socioeconomic status, more elderly and more likely to have chronic illness. Many people with DM have already experienced complications and are being cared for at the secondary level. They may have different levels of awareness of DR. This is the subject of another study.

Subjects' awareness of potential complications and their prevention is a potentially modifiable risk factor that might be improved through education. It would be useful to incorporate the need for screening and that it should be regularly scheduled, as the two most important awareness predictors for attendance found in our study, into education and/or self-management programmes for DM. A systematic review found that increasing patient awareness of DR was an effective intervention to increase screening attendance. ${ }^{33}$ Once the subjects with DM are aware of DR and the need for regular screening, barriers to attendance may be reduced. This will be important in HK, where systematic screening has been set up, and also in other places such as mainland China. China has the largest number of people with diabetes in the world, numbering 114.4 million people in $2017 .{ }^{34} \mathrm{DR}$, one of the potential complications of diabetes, substantially contributes to the risk of blindness in the Chinese diabetic population. Early detection by screening and timely treatment for STDR are effective in preventing blindness, as the successful experience from Iceland and the UK has shown. However, one of the key steps is for people with DM to attend DR screening. Given the relative underdevelopment of primary care in China, DR screening needs to rely more on self-seeking behaviour and awareness plays a key role. Why people attend screening and what influences attendance are important questions and have implications on diabetes management. Future education interventions should include raising awareness, for example, of the importance of screening and of the frequency of screening.

In conclusion, deficits in knowledge of DR and screening were found in subjects with DM, and three awareness factors were significantly associated with 
attendance for screening. Future interventions should include raising awareness.

Acknowledgements We thank Christina Chan and Joe Lee, who helped to design the questionnaire and collect the data for this study.

Contributors JXL analysed and interpreted the data and wrote the manuscript. SMM contributed to the design of the work, interpretation of data and revised the manuscript critically for important intellectual content. RAG contributed to the acquisition of the data and revised the manuscript critically. CLKM, MKHY and DSHW substantially contributed to the design of the work, acquisition of data and revised it critically for important content. All authors approved the final version to be published.

Funding This work was supported by the Health and Health Services Research Fund of the Hong Kong SAR Government (HHSRF: 06071021) and the Azalea (1972) Endowment Fund. The funding sources had no role in design or conduct of this research.

Competing interests None declared.

Patient consent Obtained.

Ethics approval Ethics approval was obtained from the Institutional Review Board of The University of Hong Kong and HA West Cluster (Institutional Review Board Reference Number UW08-134).

Provenance and peer review Not commissioned; externally peer reviewed. Data sharing statement № additional data available.

Open Access This is an Open Access article distributed in accordance with the Creative Commons Attribution Non Commercial (CC BY-NC 4.0) license, which permits others to distribute, remix, adapt, build upon this work non-commercially, and license their derivative works on different terms, provided the original work is properly cited and the use is non-commercial. See: http://creativecommons.org/ licenses/by-nc/4.0/

(c) Article author(s) (or their employer(s) unless otherwise stated in the text of the article) 2018. All rights reserved. No commercial use is permitted unless otherwise expressly granted.

\section{REFERENCES}

1. World Health Organization. Screening. http://www.who.int/cancer/ prevention/diagnosis-screening/screening/en/ (accessed 13 Dec 2017).

2. Dervan $\mathrm{E}$, Lillis $\mathrm{D}$, Flynn L, et al. Factors that influence the patient uptake of diabetic retinopathy screening. Ir J Med Sci 2008;177:303-8.

3. Green L, Kreuter M. Health promotion planning. 3rd ed. Mountain View: Mayfield Publishing Company, 1999.

4. National Diabetes Data Group. Diabetes in America. 2nd edition. Bethesda, MD: National Institutes of Health, National Institute of Diabetes and Digestive and Kidney Diseases, 1995.

5. Stefánsson E, Bek T, Porta M, et al. Screening and prevention of diabetic blindness. Acta Ophthalmol Scand 2000;78:374-85.

6. Peto $\mathrm{T}$, Tadros $\mathrm{C}$. Screening for diabetic retinopathy and diabetic macular edema in the United Kingdom. Curr Diab Rep 2012;12:338-45.

7. Thomas RL, Luzio SD, North RV, et al. Retrospective analysis of newly recorded certifications of visual impairment due to diabetic retinopathy in Wales during 2007-2015. BMJ Open 2017;7:e015024.

8. Javitt JC, Aiello LP. Cost-effectiveness of detecting and treating diabetic retinopathy. Ann Intern Med 1996;124(1 Pt 2):164-9.

9. James M, Turner DA, Broadbent DM, et al. Cost effectiveness analysis of screening for sight threatening diabetic eye disease. BMJ 2000;320:1627-31.

10. Vijan S, Hofer TP, Hayward RA. Cost-utility analysis of screening intervals for diabetic retinopathy in patients with type 2 diabetes mellitus. JAMA 2000;283:889-96.

11. American Academy of Ophthalmology Retina/Vitreous Panel. Preferred practice pattern guidelines. Diabetic retinopathy. San
Francisco, CA: American Academy of Ophthalmology, 2016. www. aao.org/ppp. (accessed 22 May 2017).

12. The Royal College of Ophthalmologists. Diabetic retinopathy guidelines. https://www.rcophth.ac.uk/wp-content/uploads/2014/ 12/2013-SCI-301-FINAL-DR-GUIDELINES-DEC-2012-updated-July2013.pdf (accessed 22 May 2017).

13. American Diabetes Association. Erratum. Microvascular Complications and Foot Care. Sec. 10. InStandards of Medical Care in Diabetes-2017. Diabetes Care 2017;40(Suppl. 1);S88-S98. Diabetes Care 2017;40:986.

14. Sheppler CR, Lambert WE, Gardiner SK, et al. Predicting adherence to diabetic eye examinations: development of the compliance withAnnual Diabetic Eye Exams Survey. Ophthalmology 2014;121:1212-9.

15. Schoenfeld ER, Greene JM, Wu SY, et al. Patterns of adherence to diabetes vision care guidelines: baseline findings from the Diabetic Retinopathy Awareness Program. Ophthalmology 2001;108:563-71.

16. Cetin EN, Zencir M, Fenkçi S, et al. Assessment of awareness of diabetic retinopathy and utilization of eye care services among Turkish diabetic patients. Prim Care Diabetes 2013;7:297-302.

17. van Eijk KN, Blom JW, Gussekloo J, et al. Diabetic retinopathy screening in patients with diabetes mellitus in primary care: Incentives and barriers to screening attendance. Diabetes Res Clin Pract 2012;96:10-16.

18. Paz SH, Varma R, Klein R, et al. Noncompliance with vision care guidelines in Latinos with type 2 diabetes mellitus: the Los Angeles Latino Eye Study. Ophthalmology 2006;113:1372-7.

19. Lindenmeyer A, Sturt JA, Hipwell A, et al. Influence of primary care practices on patients' uptake of diabetic retinopathy screening: a qualitative case study. Br J Gen Pract 2014;64:e484-e492.

20. Forster AS, Forbes A, Dodhia $\mathrm{H}$, et al. Non-attendance at diabetic eye screening and risk of sight-threatening diabetic retinopathy: a population-based cohort study. Diabetologia 2013;56:2187-93.

21. Waqar S, Bullen G, Chant S, et al. Cost implications, deprivation and geodemographic segmentation analysis of non-attenders (DNA) in an established diabetic retinopathy screening programme. Diabetes Metab Syndr 2012;6:199-202.

22. Scanlon PH, Aldington SJ, Stratton IM. Delay in diabetic retinopathy screening increases the rate of detection of referable diabetic retinopathy. Diabet Med 2014;31:439-42.

23. Trento M, Bajardi M, Borgo E, et al. Perceptions of diabetic retinopathy and screening procedures among diabetic people. Diabet Med 2002;19:810-3.

24. Liu L, Chen L. Awareness of diabetic retinopathy is the key step for early prevention, diagnosis and treatment of this disease in China. Patient Educ Couns 2014;94:284-5.

25. Walker EA, Basch CE, Howard CJ, et al. Incentives and barriers to retinopathy screening among African-Americans with diabetes. $J$ Diabetes Complications 1997;11:298-306.

26. Funatsu H, Hori S, Shimizu E, et al. Questionnaire survey on periodic ocular examination in Japanese diabetic patients. Am J Ophthalmol 2003;136:955-7.

27. Lin S, Ramulu P, Lamoureux EL, et al. Addressing risk factors, screening, and preventative treatment for diabetic retinopathy in developing countries: a review. Clin Exp Ophthalmol 2016;44:300-20.

28. Moss SE, Klein R, Klein BE. Factors associated with having eye examinations in persons with diabetes. Arch Fam Med 1995;4:529-34

29. Wang D, Ding X, He M, et al. Use of eye care services among diabetic patients in urban and rural China. Ophthalmology 2010;117:1755-62.

30. Lian JX, McGhee SM, Gangwani RA, et al. Screening for diabetic retinopathy with or without a copayment in a randomized controlled trial: influence of the inverse care law. Ophthalmology 2013;120:1247-53.

31. Lian J, McGhee SM, Gangwani RA, et al. The impact of a copayment on the cost-effectiveness of screening for diabetic retinopathy. J Public Health 2016;38:782-792.

32. Rand Corporation. National Eye Institute Visual Functioning Questionnaire-25 (VFQ-25): Rand Corporation, 1996. https://nei.nih. $\mathrm{gov} /$ sites/default/files/nei-pdfs/vfq_sa.pdf

33. Zhang X, Norris SL, Saadine J, et al. Effectiveness of interventions to promote screening for diabetic retinopathy. Am J Prev Med 2007;33:318-35.

34. International Diabetes Federation. IDF diabetes atlas. Eighth edition, 2017. http://www. diabetesatlas.org/ (accessed 15 Dec 2017). 